\title{
Structural Dynamic Response of a Shield Tunnel under Aircraft Taxiing Load
}

\author{
Zhanyou Luo $\mathbb{D}$, ${ }^{1,2,3}$ Kuangqin Xie $\mathbb{D}^{1},{ }^{1}$ Baoping Zou $\left(\mathbb{D},{ }^{1}\right.$ Mingyao Jiang $\mathbb{D}^{1}{ }^{1}$ \\ and Wei Zheng iD 1 \\ ${ }^{1}$ Tunnel and Underground Space Academy, Zhejiang University of Science and Technology, Hangzhou 310023, Zhejiang, China \\ ${ }^{2}$ Institute of Rock Mechanics, Ningbo University, Ningbo 315211, Zhejiang, China \\ ${ }^{3}$ Department of Civil Engineering, Shaoxing University, Shaoxing 312000, Zhejiang, China
}

Correspondence should be addressed to Zhanyou Luo; lzy0395@163.com

Received 21 July 2021; Accepted 10 September 2021; Published 24 September 2021

Academic Editor: Guangjian Liu

Copyright (C) 2021 Zhanyou Luo et al. This is an open access article distributed under the Creative Commons Attribution License, which permits unrestricted use, distribution, and reproduction in any medium, provided the original work is properly cited.

Dynamic load is an important factor affecting the safety and stability of subway tunnel structures. To obtain the variation law of shield tunnel structure dynamic response under aircraft taxiing load, a three-dimensional numerical simulation of such tunnel under the action of aircraft taxiing load is performed on the basis of a project involving a shield tunnel orthogonal underpass taxiway. The effects of sliding speed and tunnel depth on the structure of the shield tunnel are also analyzed. The results show that the transverse displacement and acceleration response of tunnel segment exhibit evident time-space effect under the action of aircraft taxiing load. The transverse displacement and arch waist acceleration of the shield segment increase first and then decrease. The transverse displacement of the arch waist reaches its maximum when the aircraft taxis directly above the tunnel. The sliding speed exhibits an evident influence on the dynamic response of shield tunnel structure. The vertical and convergence displacements of tunnel segments increase with the increase in sliding speed. The dynamic response of tunnel structure is significantly affected by the factors of tunnel buried depth. The vertical and convergence displacements of tunnel segments decrease with the increase in tunnel buried depth. Therefore, the safety of the shield tunnel structure can be ensured by controlling the taxiing speed when the aircraft taxis directly above the tunnel. The measures of increasing the buried depth of the tunnel or strengthening the tunnel structure need to be considered when the taxiing speed is large.

\section{Introduction}

Subway construction has effectively solved the problem of urban traffic congestion and has become the main way to effectively improve the function of the airport comprehensive transportation hubs. Given that aircraft load is a dynamic load that has a significant effect on the safety of shield tunnel structure, the structural dynamic response of a shield tunnel under aircraft taxiing load must be studied $[1,2]$.

A number of undercrossing projects in aircraft movement areas have been successfully implemented in China and abroad; these projects include the Taipei Songshan Airport municipal road undercrossing project in an operating runway $[3,4]$, the Shanghai Rail Transit Line 10 undercrossing project in Hongqiao Airport's runway [5], the Beijing Capital
International Airport $L$ taxiway crossing project [6], the British airport cargo corridor project [7], the German mining method tunnel undercrossing in an airport runway [8], and the Chengdu Metro Line 10 crossing in Chengdu Shuangliu International Airport [9]. With the increase in number of undercrossing projects in airports, scholars have conducted considerable research on tunnel projects in aircraft movement areas. Luo et al. [10] analyzed the variation law of horizontal and lateral displacement of soil under load based on the strain path and source-sink methods. Wang et al. [11] deduced the additional stress formula at any soil depth under aircraft load by using Boussinesq's solution and elastic layered theory. Under the premise that the tunnel surface structure of an aircraft movement area is coordinated and deformed with the subsidence of the foundation, Zhang et al. [12] developed the 
control formula in which shield construction causes no an antislope problem in the tunnel structure when crossing the runway of an aircraft movement area. Zhang et al. [13] used three-dimensional (3D) finite element numerical simulation to obtain the runway subsidence law caused by an underpassing in a two-line shield tunnel.

The above research mainly focused on the influences of tunnel excavation on structures and surface settlement in the airport area. However, studies on the structural properties of the shield tunnel under aircraft load are limited. Aircraft load will have an adverse effect on the tunnel when the tunnel structure is in the muddy stratum. Therefore, ensuring the stability of tunnel structure and surrounding soil under aircraft taxiing load is an important problem. In this paper, the numerical simulation method is used to study the variation law of taxiing speed on the dynamic response of tunnel segments and analyze the dynamic response of tunnel segments under different buried depths. The deformation law of the existing tunnel under aircraft taxiing load is obtained, and the acquired findings are important to the design, construction, and operation of subway tunnels and provide reference for similar projects.

\section{Project Background}

A shield tunnel exists under the operated airport. The aircraft movement area has the reference code $4 \mathrm{E}$. The taxiway material is asphalt concrete, with a thickness of $1 \mathrm{~m}$, and the taxiway has a natural foundation. The field foundation soil is divided into five engineering geological layers in accordance with the results of drilling, in situ test, and laboratory test. From top to bottom, the layers are plain fill, sandy silt, silt, mucky clay, and muddy silt clay. The entire tunnel is in the mucky clay layer, which has the characteristics of large layer thickness, low strength, high compressibility, and poor engineering properties. The total length of the shield section is approximately $3,274 \mathrm{~m}$, with a buried depth of $10-18 \mathrm{~m}$ and a diameter of $6.2 \mathrm{~m}$. The width of the single ring segment is $1.2 \mathrm{~m}$, with a thickness of $350 \mathrm{~mm}$. The shield section crosses the taxiway at the position of $\mathrm{K} 51+039.788$ $\mathrm{K} 51+315.216$ on the right line and $\mathrm{K} 51+050.228$ $\mathrm{K} 51+323.346$ on the left line. Figure 1 illustrates the position relationship between the shield tunnel and taxiway.

\section{Determination of Aircraft Load}

Aircraft taxiing load refers to the dynamic load generated by aircraft self-weight and acceleration on the taxiway during takeoff and landing. The aircraft load is mainly borne by the main landing gear in accordance with the load distribution factor and transmitted to the pavement through tires. The main landing gear usually is uniaxial and double-wheeled, biaxial and double-wheeled, and triaxial and doublewheeled [14]. To simulate the adverse effect of taxiing load on tunnel structure to the greatest extent, the maximum aircraft A380-800F is selected as the calculation parameter, and its maximum takeoff weight is $5600 \mathrm{kN}$. Figure 2 shows the tire layout of the A380-800F model, and Table 1 provides the aircraft calculation parameters.
3.1. Wheel Pressure of the Single Tire of an Aircraft. The wheel load on the main landing gear of the aircraft is calculated accordance with the following formula [15]:

$$
P_{t}=\frac{G p}{n_{c} n_{w}},
$$

where $P_{t}$ is the wheel load assigned to a single tire on the main landing gear, $\mathrm{kN} ; G$ is the aircraft quality, $t ; p$ is the distribution factor of the main landing gear load; $n_{c}$ represents the number of main landing gears; and $n_{w}$ represents the number of wheels on a landing gear.

3.2. Calculated Size of Aircraft Wheel Prints. To facilitate the establishment of the model, the wheel printing is simplified into a rectangle using the following equations [15] and in accordance with the principle of area equivalence:

$$
\begin{gathered}
L_{t}=\sqrt{\frac{P_{t} \times 10^{4}}{5.227 q}}, \\
W_{t}=0.6 L_{t},
\end{gathered}
$$

where $L_{t}$ is the length of the aircraft wheel prints, $W_{t}$ is the width of the aircraft wheel prints, and $q$ is the tire pressure.

Figure 3 shows the shape of aircraft wheel prints.

\section{3D Numerical Simulation of the Dynamic Response of Shield Tunnel under Aircraft Load}

4.1. Establishment of 3D Finite Element Model. In this paper, a $3 \mathrm{D}$ numerical model of dynamic response of the shield tunnel under aircraft load is established using finite element software. The model is mainly composed of aircraft load, taxiway, and shield tunnel. According to the actual project, the buried depth of the tunnel is $10 \mathrm{~m}$, the diameter is $6.2 \mathrm{~m}$, the segment thickness is $350 \mathrm{~mm}$, and the single ring segment width is $1.2 \mathrm{~m}$.

The aircraft load is simplified as the surface load acting on the taxiway, and the directional displacement is specified to simulate the aircraft taxiing. To reduce the influence of boundary on the model, the size of the 3D numerical model is set as $30 \mathrm{~m} \times 90 \mathrm{~m} \times 40 \mathrm{~m}$. In addition, the bottom of the model adopts horizontal and normal fixed constraints, the four sides adopt horizontal fixed constraints, and the ground surface is a free boundary. Figure 4 shows the $3 \mathrm{D}$ numerical model of the shield tunnel under aircraft load.

4.2. Determination of Model Parameters. According to the actual project, the foundation soil in the site area is plain fill, sandy silt, silt, mucky clay, and muddy silt clay from top to bottom. Assume that all the soil layers are distributed inhomogeneous horizontal regions. Soil layers of the same type and with similar basic parameters are simplified by combining and simplifying the weighted average algorithm. The small-strain soil hardening (HSS) constitutive model $[16,17]$ is selected for mucky clay, and the specific 


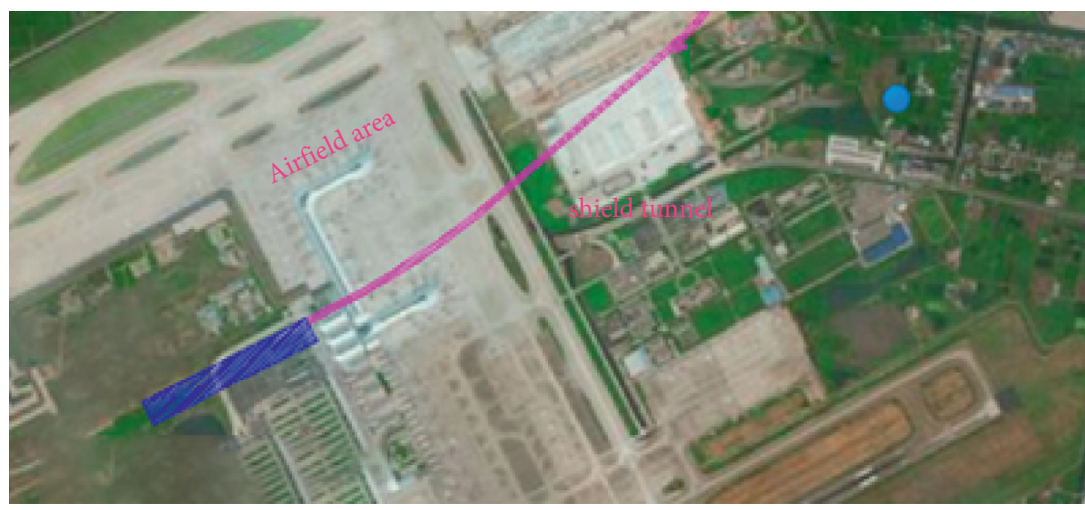

(a)

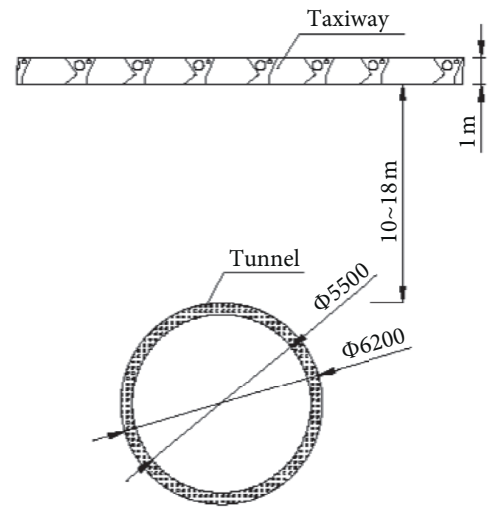

(b)

Figure 1: Location relationship between the shield tunnel and airport taxiway. (a) Plan. (b) Section.

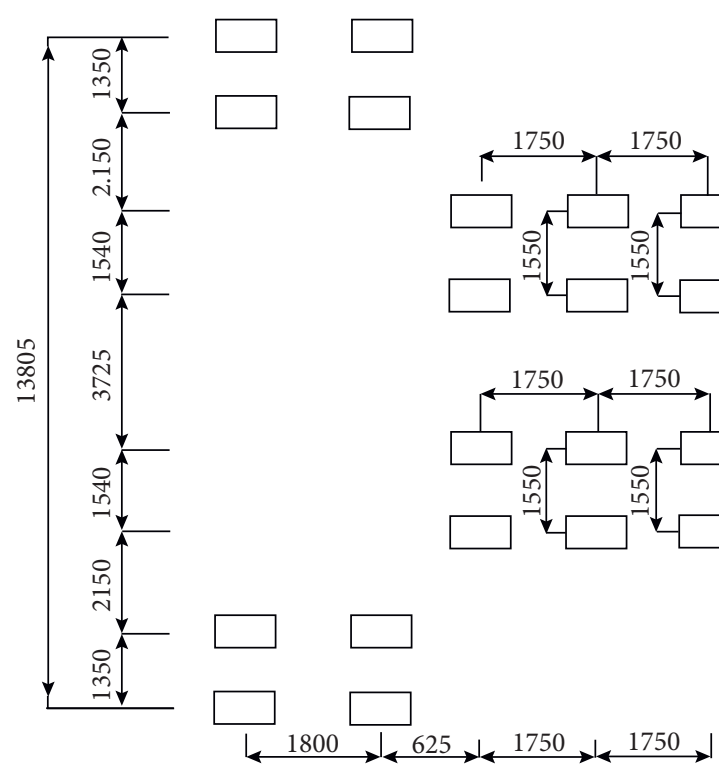

(a)

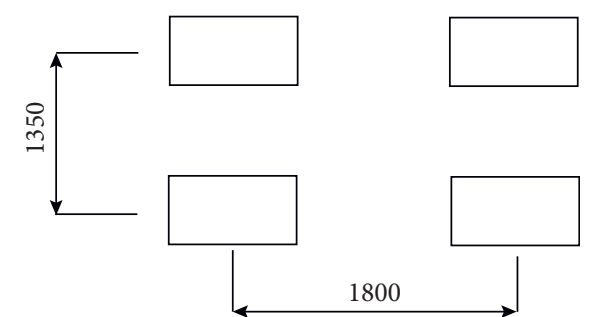

(b)

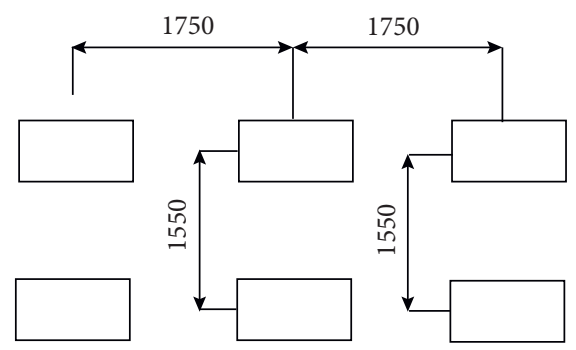

(c)

Figure 2: (a) Tire layout of the A380-800F model. (b) Biaxial and double-wheeled. (c) Triaxial and double-wheeled.

parameters are shown in Table 2. The Mohr-Coulomb (MC) constitutive model is selected for plain fill, sandy silt, silt, and muddy silty clay. Table 3 shows the specific physical and mechanical parameters of soil. Among the parameters, $H$ is the thickness of the soil layer, $c$ is the cohesive force of the soil mass, $\varphi$ is the friction angle in the soil, $E_{\text {ode }}^{\text {ref }}$ is the tangent modulus of the consolidation test, $E_{50}^{\text {ref }}$ is the secant modulus, $E_{\mathrm{ur}}^{\mathrm{ref}}$ is the unload-reload modulus, $\gamma_{0.7}$ is the shear strain threshold, $G_{0}^{\text {ref }}$ is the small-strain shear modulus, $m$ is the power exponent, $\gamma$ is the natural gravity, $\gamma_{\text {sat }}$ is the saturation gravity, $E$ is the elastic modulus, and $v$ is Poisson's ratio.

Given that the aircraft load acts on the airport pavement through tires, the aircraft load is simplified as surface load, and its position is determined by the actual aircraft wheel seal. Aircraft taxiing is realized through the change in surface load position. To maximize the adverse effect of taxiing load 
TABle 1: Aircraft parameters.

\begin{tabular}{|c|c|c|}
\hline Parameters & \multicolumn{2}{|c|}{ A380-800F } \\
\hline Maximum takeoff weight $(\mathrm{kN})$ & \multicolumn{2}{|c|}{5600} \\
\hline Empty weight $(\mathrm{kN})$ & \multicolumn{2}{|c|}{2800} \\
\hline The load distribution coefficient of main landing gears & \multicolumn{2}{|c|}{0.97} \\
\hline Number of main landing gears & \multicolumn{2}{|c|}{4} \\
\hline Main landing gear structure & Biaxial and double-wheeled & Triaxial and double-wheeled \\
\hline Main landing gear wheelbase (m) & $1.35 / 1.8$ & $1.55 / 1.75$ \\
\hline Main landing gear maximum tire pressure $(\mathrm{MPa})$ & \multicolumn{2}{|c|}{1.47} \\
\hline Main landing gear minimum tire pressure $(\mathrm{MPa})$ & \multicolumn{2}{|c|}{0.735} \\
\hline Main landing gear single-wheel load $(\mathrm{kN})$ & \multicolumn{2}{|c|}{271.6} \\
\hline Main landing gear wheel print area $\left(\mathrm{m}^{2}\right)$ & \multicolumn{2}{|c|}{0.183} \\
\hline Main landing gear wheel print length $(\mathrm{m})$ & \multicolumn{2}{|c|}{0.594} \\
\hline
\end{tabular}

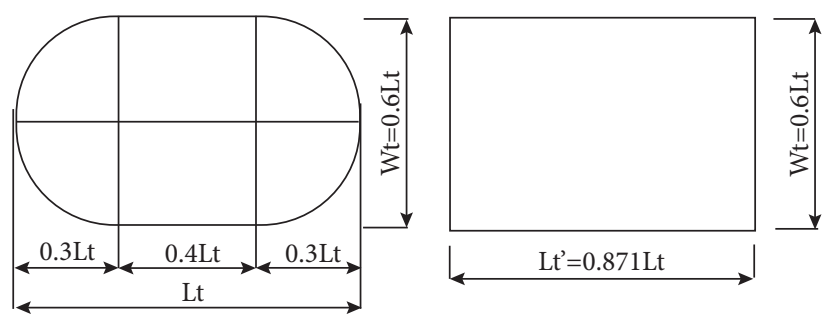

FIGURE 3: Shape of aircraft wheel prints.

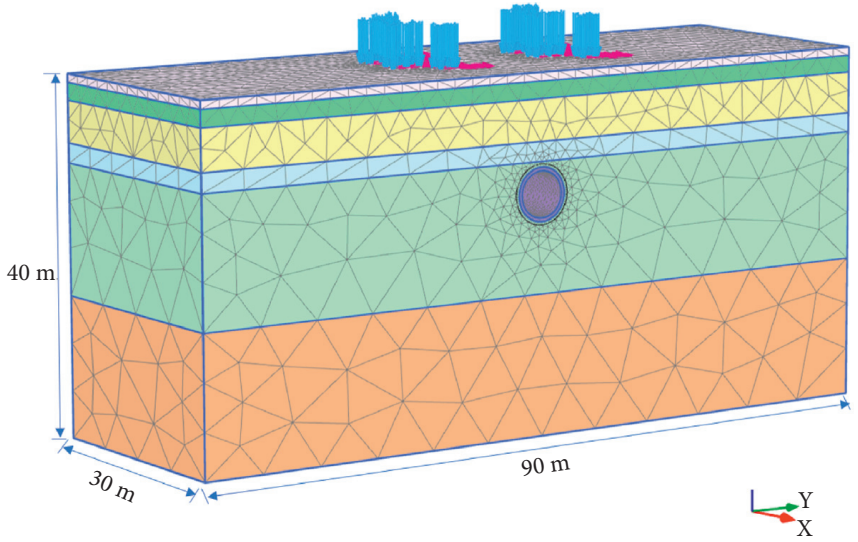

(a)
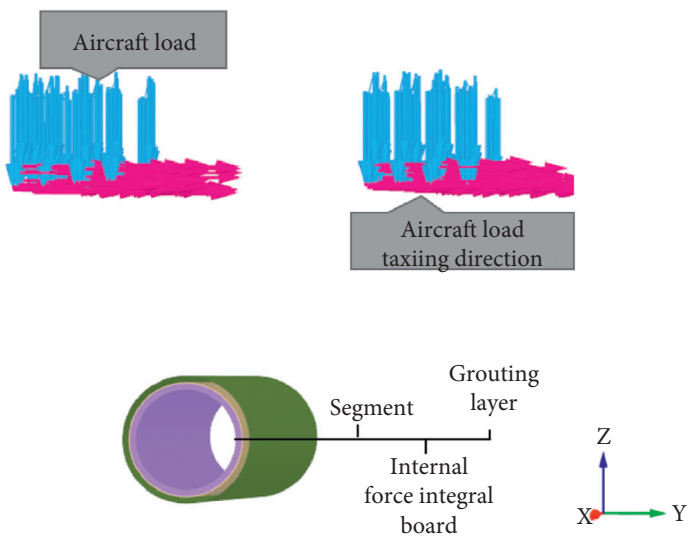

(b)

Figure 4: 3D numerical model. (a) 3D view. (b) Partially enlarged view of the tunnel and load position.

TABLE 2: Parameters of the hardening constitutive model of mucky clay.

\begin{tabular}{lccccccccc}
\hline Name of soil layer & $H(\mathrm{~m})$ & $C(\mathrm{kPa})$ & $\varphi^{\circ}$ & $E_{\text {o de }}^{\text {ref }}(\mathrm{MPa})$ & $E_{50}^{\text {ref }}(\mathrm{MPa})$ & $E_{u r}^{\text {ref }}(\mathrm{MPa})$ & $\gamma_{0.7}$ & $G_{0}^{\text {ref }}(\mathrm{MPa})$ & $\mathrm{m}$ \\
\hline Mucky clay & 15.3 & 12 & 25 & 2.34 & 2.26 & 15.7 & 0.0002 & 30 & 0.5 \\
\hline
\end{tabular}

TABle 3: Physical and mechanical parameters of soil layer.

\begin{tabular}{lccccrr}
\hline Name of soil layer & $H(\mathrm{~m})$ & $\Gamma\left(\mathrm{kN} / \mathrm{m}^{3}\right)$ & $\gamma_{\text {sat }}\left(\mathrm{kN} / \mathrm{m}^{3}\right)$ & $E(\mathrm{MPa})$ & $C(\mathrm{kPa})$ & $\Phi\left(^{\circ}\right)$ \\
\hline Plain fill & 3.00 & 12.00 & 17.00 & 3.00 & 10.00 & 15 \\
Sandy silt & 4.90 & 17.00 & 19.20 & 8.50 & 0.00 & 30 \\
Silt & 2.30 & 17.00 & 18.40 & 12.00 & 5.20 & 32 \\
Muddy silt clay & 16.50 & 15.80 & 17.60 & 5.00 & 18.80 & 0.30 \\
\hline
\end{tabular}


on tunnel structure [18], the maximum aircraft load and taxiing speed are selected as basic parameters. The specific parameters are shown in Table 4.

In accordance with existing research results [19], the additional stress generated under the flexible pavement of asphalt concrete under the action of aircraft load will be greater than that generated under the rigid pavement of cement concrete. Therefore, the constitutive M-C model is adopted for the airport pavement in this numerical model.

The constitutive M-C model is adopted for the grouting layer of the shield tunnel, and the contact surface is set between the segment and the grouting layer. The segment is simulated by solid element + plate element. The stiffness of the segment is reduced to $75 \%$ to consider the weakening of the overall stiffness of the connector. To facilitate the internal force output of the segment, a layer of the flexible plate element is placed inside the segment's solid element. Its stiffness is regarded as 1/1000 that of the segment, and thus the internal force of the surrounding solid element can be obtained on the basis of the plate element without affecting the force of the segment's solid element. To obtain the changes in displacement and internal force of shield tunnel structure under aircraft taxiing, the monitoring points are arranged at the central arch crown, arch waist, and arch bottom of the tunnel, as shown in Figure 5. Table 5 shows the material parameters of pavement, segment, and grouting layer, and Table 6 provides the plate elements.

\subsection{Analysis of Numerical Simulation Results}

4.3.1. Tunnel Segment Displacement. Figure 6 shows the displacement distribution of shield tunnel segments under the action of aircraft taxiing load. The time-history curves of tunnel segment monitoring points are extracted and illustrated in Figure 7. Figures 6 and 7 show that the displacement of tunnel segments exhibits an evident space-time effect under the action of aircraft taxiing load. Different positions of the ring segment in the shield tunnel have settlement under the action of aircraft taxiing load, in which the maximum settlement of the arch crown is $128.1 \mathrm{~mm}$, followed by the arch waist $(95.9 \mathrm{~mm})$. The transverse displacement of shield segments increases first and then decreases. When the aircraft taxis directly above the tunnel, the maximum transverse displacement of the arch waist on the left and right sides of the middle ring of the tunnel is $-12.9 \mathrm{~mm}$ and $16.3 \mathrm{~mm}$, respectively.

4.3.2. Acceleration of Tunnel Segment. Figure 8 shows the acceleration time-history curve at the waist of the ring arch in the shield tunnel under the aircraft taxiing load. Figure 8 also reveals that with the taxiing of the aircraft, the acceleration of the tunnel structure fluctuates greatly before $0.06 \mathrm{~s}$. At $0.06-0.13^{\circ} \mathrm{s}$, the acceleration of the arch waist increases first and then decreases. The acceleration reaches the peak when the aircraft taxis directly above the tunnel, at which the maximum acceleration on the right side of the tunnel is $0.38 \mathrm{~cm} / \mathrm{s}^{2}$ which is greater than the maximum acceleration on the left side $\left(0.22 \mathrm{~cm} / \mathrm{s}^{2}\right)$.
TABLE 4: Aircraft load parameters.

\begin{tabular}{lccc}
\hline $\begin{array}{l}\text { Parameter } \\
\text { name }\end{array}$ & $\begin{array}{c}\text { Load } \\
(\mathrm{MPa})\end{array}$ & $\begin{array}{c}\text { Taxi speed } \\
(\text { section })\end{array}$ & $\begin{array}{c}\text { Taxi distance } \\
(\mathrm{m})\end{array}$ \\
\hline Value & 1.47 & 200 & 20 \\
\hline
\end{tabular}

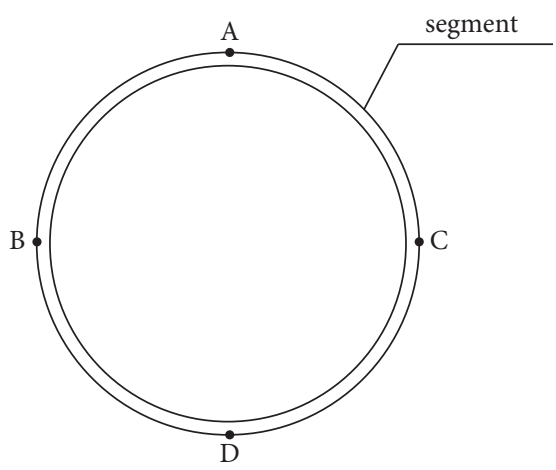

FIgURE 5: Layout of monitoring points.

TABLE 5: Parameters of segment and grouting material.

\begin{tabular}{lccc}
\hline Parameters & Segment & Grouting layer & Pavement \\
\hline Material model & Linear elasticity & M-C & M-C \\
Element type & Solid element & Solid element & Solid element \\
$\gamma\left(\mathrm{kN} / \mathrm{m}^{3}\right)$ & 25 & 14 & 25 \\
$E\left(\mathrm{kN} / \mathrm{m}^{2}\right)$ & $28.5 e 6$ & $20 e 3$ & $26.09 e 6$ \\
$\mathrm{v}$ & 0.2 & - & - \\
$c\left(\mathrm{kN} / \mathrm{m}^{2}\right)$ & - & 1030 & 25 \\
$\Phi\left(^{\circ}\right)$ & - & 45 & 18 \\
\hline
\end{tabular}

4.3.3. Soil Hardening Effect. The mucky clay is shear hardened under aircraft taxiing load, which affects the structural properties of the tunnel. Figure 9 shows the distribution of soil shear hardening around the tunnel under aircraft load. Figure 9 also reveals that the shear hardening of soil around the tunnel mainly occurs at the arch foot without aircraft load and is conically distributed along with the tunnel trend. When the aircraft applies taxiing load on the ground, the shear hardening of soil is mainly concentrated in the upper part of the tunnel and the soil around the arch bottom. The shear hardening of the soil mass becomes denser with the decrease in distance from the tunnel.

\section{Discussion}

Aircraft taxiing load has a significant effect on tunnel structure. Based on the model established above, the variation law of sliding speed on the dynamic response of tunnel segments is studied, and the dynamic response of tunnel segments under different buried depths is analyzed.

5.1. Influence of Aircraft Taxiing Speed. According to the takeoff and landing speeds of civil aircraft, three groups of control groups with different taxiing speeds are set. The specific parameters are shown in Table 7. 
TABLE 6: Material parameters of the plate element.

\begin{tabular}{lccccc}
\hline Parameters & $\gamma\left(\mathrm{kN} / \mathrm{m}^{3}\right)$ & $d(\mathrm{~m})$ & $E\left(\mathrm{kN} / \mathrm{m}^{2}\right)$ & $v$ & $G\left(\mathrm{kN} / \mathrm{m}^{2}\right)$ \\
\hline Internal force integral board & 0 & 0.35 & $26.62 \mathrm{e} 3$ & 0.15 & $11.57 \mathrm{e} 3$ \\
\hline
\end{tabular}

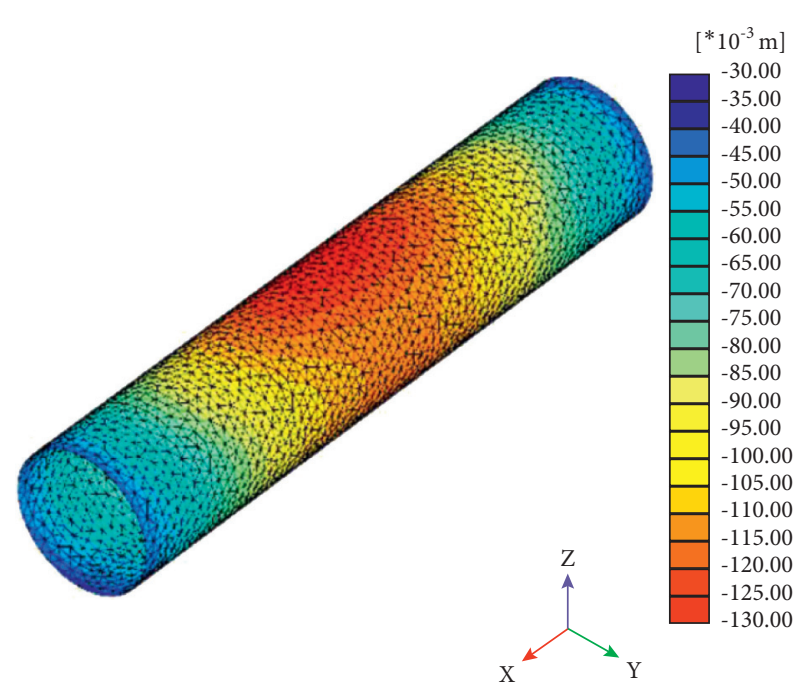

(a)

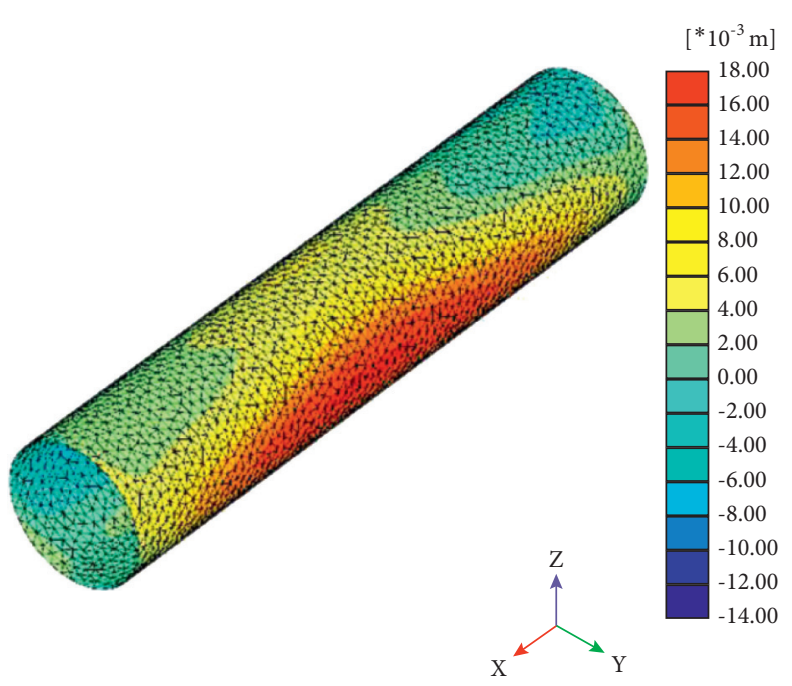

(b)

Figure 6: Displacement of tunnel segments. (a) Vertical displacement. (b) Lateral displacement.

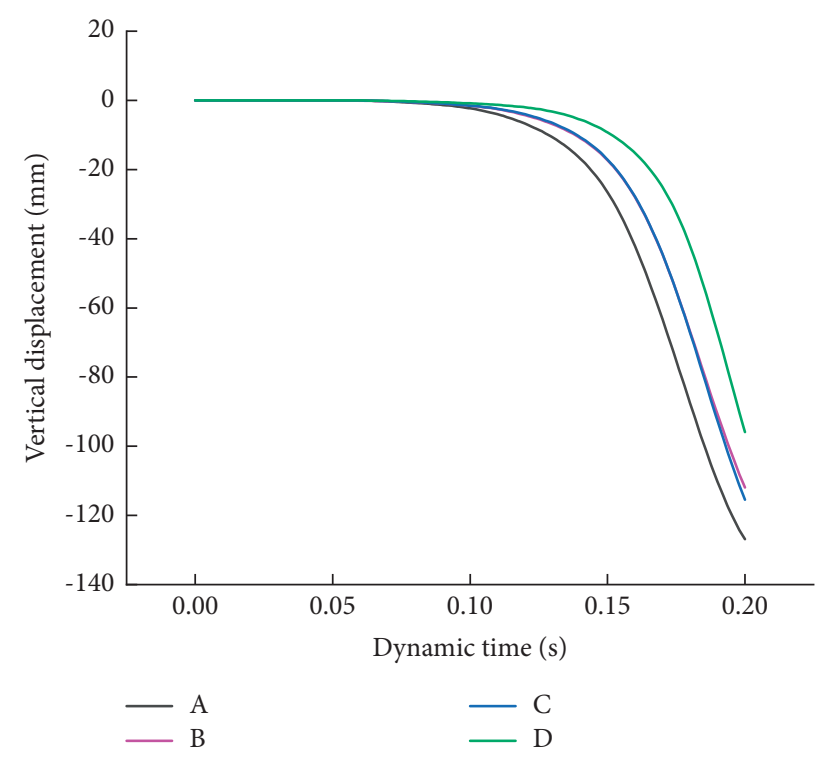

(a)

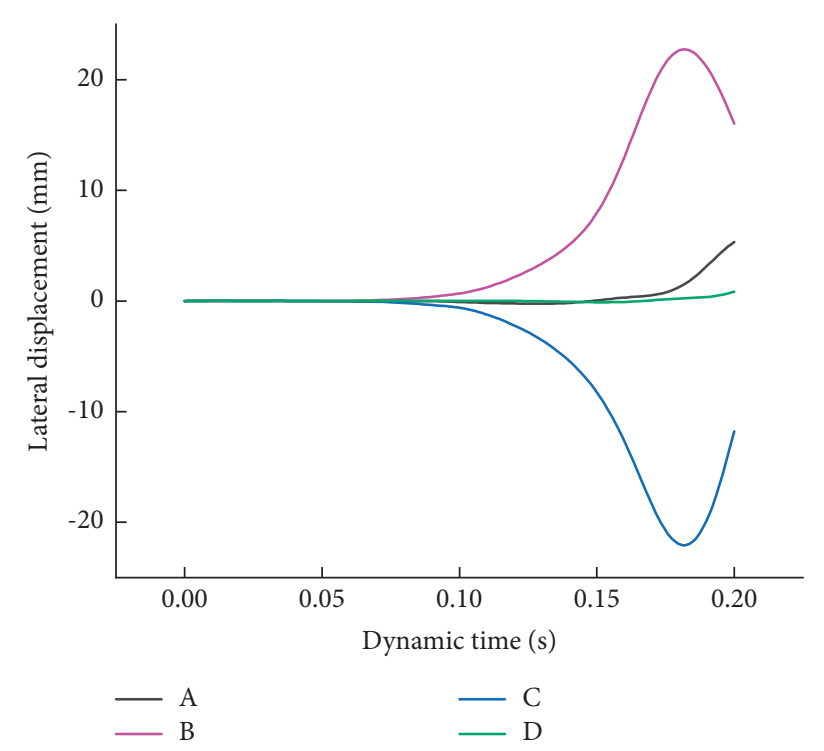

(b)

FIGURE 7: Time-history curves of the displacement of tunnel monitoring points. (a) Vertical displacement. (b) Lateral displacement.

Figure 10 shows the response time-history curve of the tunnel structure at dynamic times under the action of different taxiing speeds. Figure 10 also reveals that the maximum vertical displacements of the tunnel segments are $-126.92,-123.78,-103.78$, and $-80.27 \mathrm{~mm}$ at the sliding speeds of $200,180,150$, and $130 \mathrm{kt}$, respectively. The convergence displacement of the tunnel segments increases first and then decreases during aircraft taxiing. The maximum convergence displacements are $-44.82,-41.80,-39.24$, and $-38.35 \mathrm{~mm}$ at the taxiing speeds of $200,180,150$, and $130 \mathrm{kt}$, respectively. The vertical and convergence displacements of tunnel segments increase with the increase in sliding speed. When the sliding speed is $130 \mathrm{kt}$, the vertical and convergence displacements of the tunnel segment are 0.63 times and 0.85 times those of the sliding speed of $200 \mathrm{kt}$, respectively. 


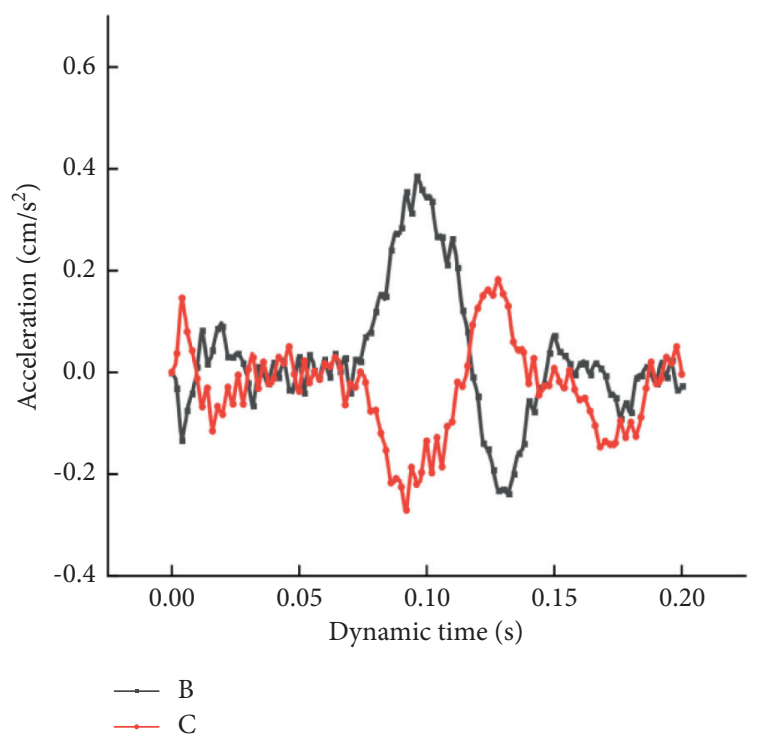

Figure 8: Acceleration time-history curve of the tunnel arch waist.

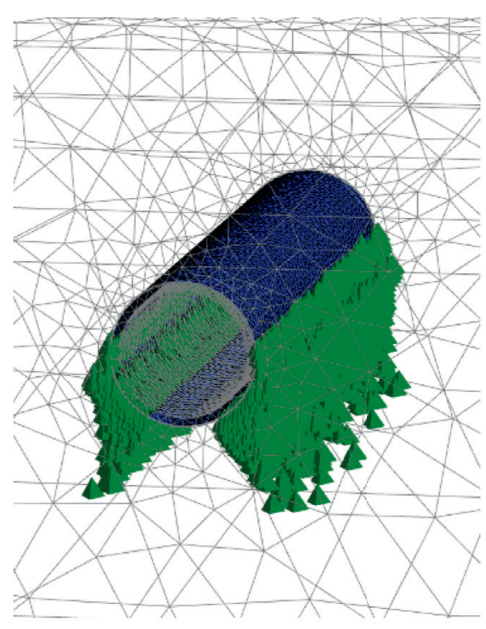

(a)

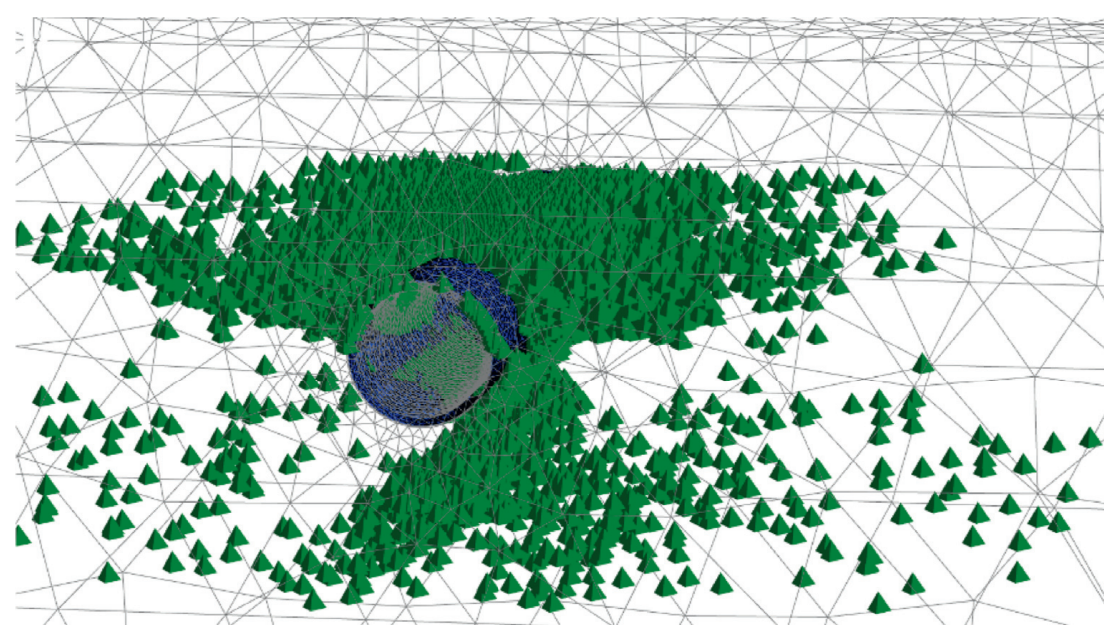

(b)

FIGURE 9: Distribution of soil hardening points around the tunnel. (a) Before the action of aircraft taxiing load. (b) After the action of aircraft taxiing load.

TABLE 7: Calculation scheme.

\begin{tabular}{|c|c|c|c|c|}
\hline & Standard group & Group 1 & Group 2 & Group 3 \\
\hline Vertical load value $(\mathrm{MPa})$ & 1.47 & 1.47 & 1.47 & 1.47 \\
\hline Aircraft taxiing speed $(\mathrm{kt})$ & 200 & 180 & 150 & 130 \\
\hline Tunnel depth (m) & 10 & 10 & 10 & 10 \\
\hline
\end{tabular}

5.2. Influence of the Buried Depth of Shield Tunnel. Given that the buried depth of the tunnel is $10-18 \mathrm{~m}$ in the actual engineering situation, four control groups of different tunnel buried depths are set. Table 8 shows the specific parameters.

Figure 11 shows the response time-history curve of tunnel segments under aircraft taxiing load at different tunnel depths. Figure 11 also reveals that the vertical and convergence displacements of tunnel segments decrease with the increase in tunnel buried depth. The maximum vertical displacements of the tunnel segment are -126.92 , $-40.13,-19.16,-8.69$, and $-0.0066 \mathrm{~mm}$ at the buried depths of $10,13,14,15$, and $18 \mathrm{~m}$, respectively. The maximum convergence displacements of the tunnel segment are $-45.84,-28.64,-13.64,-4.64$, and $-0.0087 \mathrm{~mm}$ at the buried depths of $10,13,14,15$, and $18 \mathrm{~m}$, respectively. When the buried depth of the tunnel is greater than $14 \mathrm{~m}$, the vertical and convergence displacements of the tunnel segment meet the monitoring and control requirements. 


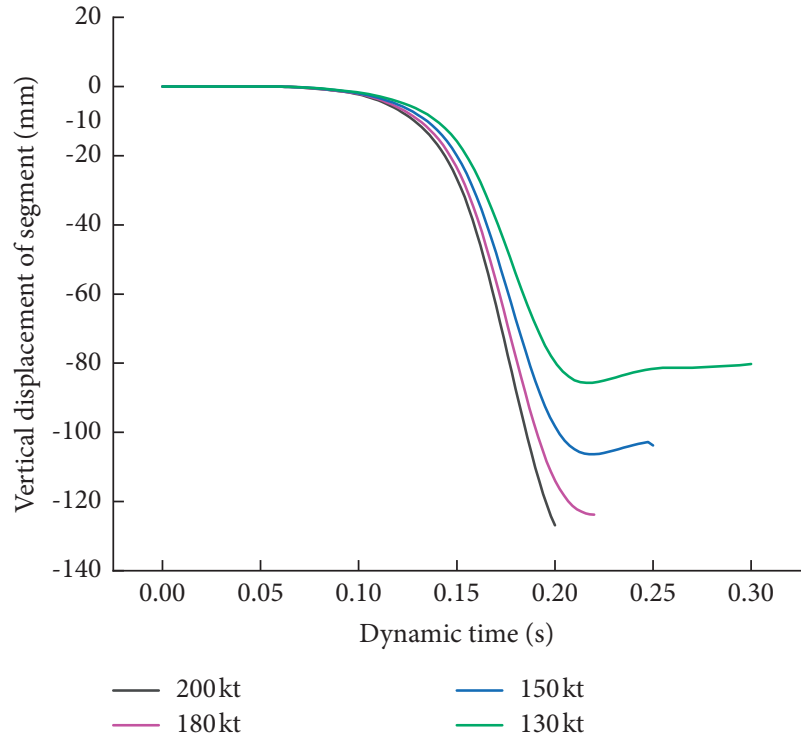

(a)

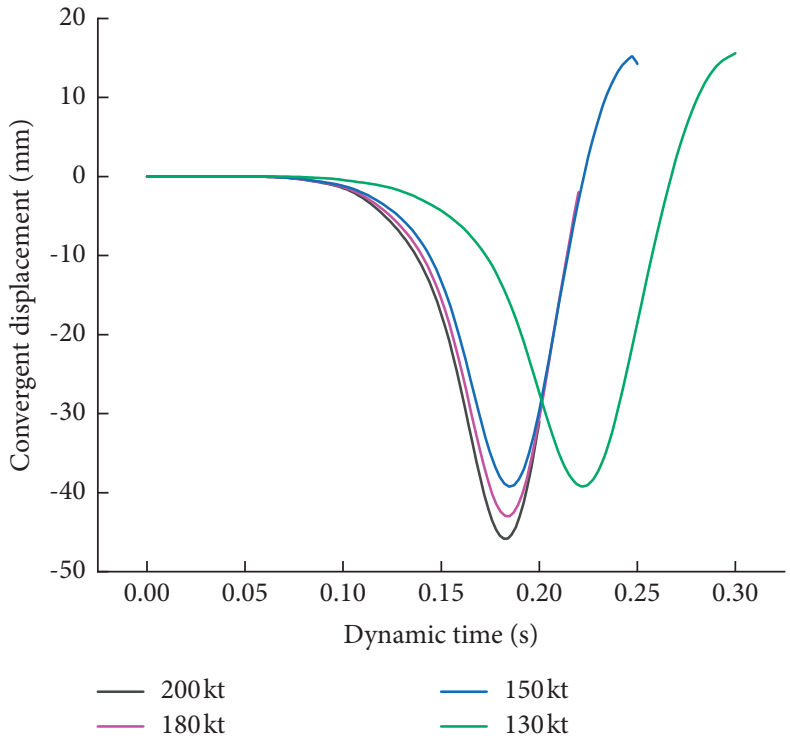

(b)

FIgURE 10: Time-history curves of deformation response of tunnel segments under different sliding speeds. (a) Vertical displacement of a segment. (b) Convergent displacement of a segment.

TABLE 8: Calculation scheme.

\begin{tabular}{|c|c|c|c|c|c|}
\hline & Standard group & Group 1 & Group 2 & Group 3 & Group 4 \\
\hline Vertical load value $(\mathrm{MPa})$ & 1.47 & 1.47 & 1.47 & 1.47 & 1.47 \\
\hline Aircraft taxiing speed $(\mathrm{kt})$ & 200 & 200 & 200 & 200 & 200 \\
\hline Tunnel depth (m) & 10 & 13 & 14 & 15 & 18 \\
\hline
\end{tabular}

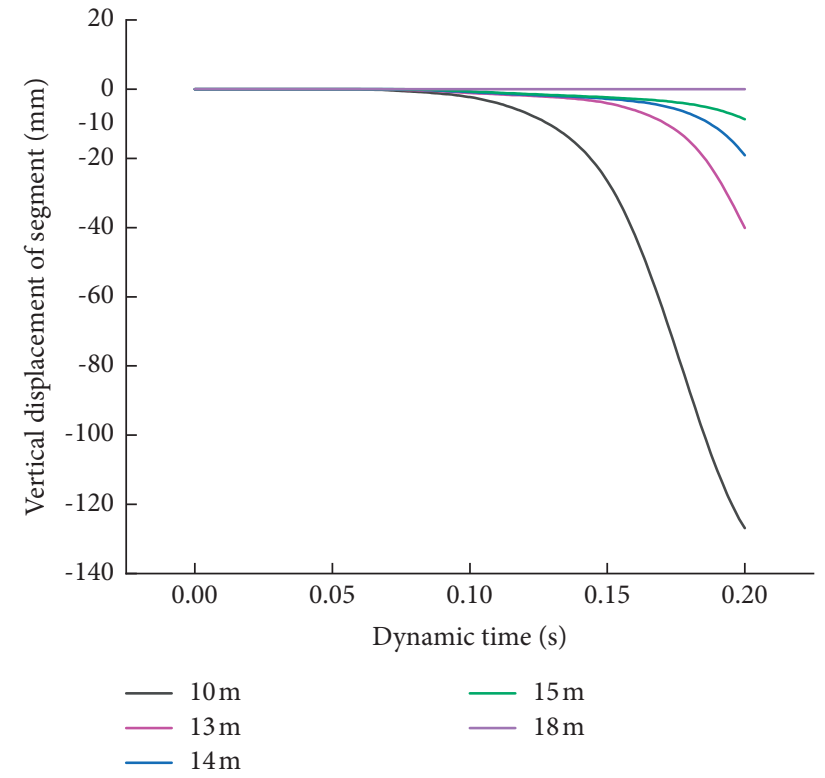

(a)

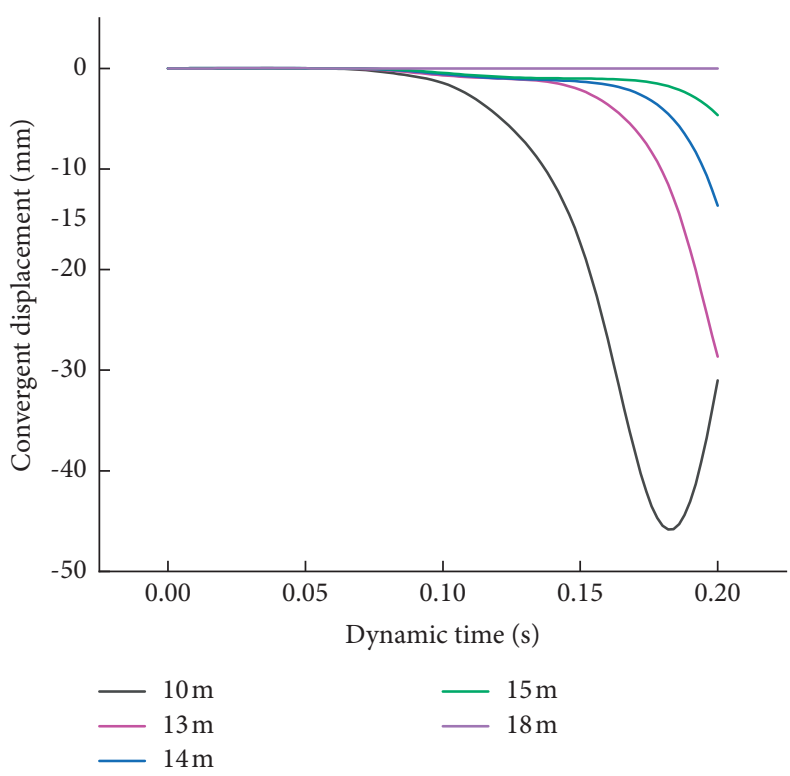

(b)

FIgURE 11: Time-history curves of deformation response of tunnel segments under different tunnel depths. (a) Vertical displacement of a segment. (b) Convergent displacement of a segment. 


\section{Conclusions}

(1) The displacement of the tunnel segment shows an evident space-time effect under the action of aircraft taxiing load. With regard to space, the vertical displacement of the vault and transverse displacement of the arch waist are the largest. On the whole, tunnel deformation represents the deformation of vault sink and the expansion on both sides. With regard to time, the transverse displacement of the arch waist first increases and then decreases with taxiing of the aircraft load. The transverse displacement of the arch waist reaches its maximum when the aircraft taxis directly above the tunnel.

(2) The acceleration response of the arch waist increases with the approaching aircraft load and decreases as the load moves away from it. The acceleration reaches the peak when the aircraft taxis directly above the tunnel, and the acceleration response on the right side of the tunnel is greater than that on the left side.

(3) The influence of sliding speed on the dynamic response of shield tunnel structure is evident. The vertical and convergence displacements of the tunnel segments increase with the increase in sliding speed. The dynamic response of the tunnel structure is significantly affected by the factors of tunnel buried depth. The vertical and convergence displacements of tunnel segments decrease with the increase in tunnel buried depth.

(4) The taxiing speed needs to be controlled when the aircraft taxis directly above the tunnel to ensure the safety of the shield tunnel structure. The measures of increasing the buried depth of the tunnel or strengthening the tunnel structure need to be considered if the taxiing speed is large.

\section{Data Availability}

All data used during the study appear in the submitted article.

\section{Conflicts of Interest}

The authors declare that there are no conflicts of interest regarding the publication of this paper.

\section{Acknowledgments}

This paper was supported by the Special Support Plan for High Level Talents of Zhejiang Province (2020R52028). Their support is gratefully acknowledged.

\section{References}

[1] X. B. Lu, Y. D. Wang, Y. F. Qiao, W. Q. Ding, B. F. Si, and C. R. Chang, "Investigation on undercrossing construction methods used in the airfield area under non-suspending condition," Modern Tunnelling Technology, vol. 55, no. S2, pp. 375-385, 2018.
[2] Q. Y. Fei, W. Q. Ding, X. B. Lu et al., "Key points in managing and constructing under crossing projects in airfield area," Earth Science Frontiers, vol. 26, no. 3, pp. 113-121, 2019.

[3] G. Y. Xiong, "The programme and design of the subway acrossing the songshan airport in north of Fuxin's road in Taibei," Journal of Fuzhou University, vol. 25, no. S1, pp. 56-60, 1997.

[4] D. J. Yao, Z. H. Wu, and Y. H. Zhang, "Design and analysis of pipe roofing method in soft clay," Chinese Journal of Rock Mechanics and Engineering, vol. 23, no. S2, pp. 4999-5005, 2004.

[5] X. Sun, S. M. Liao, S. X. Mi, and W. Shao, "Introduction of three tunnels passing under flight zone of Shanghai Hongqiao airport," Underground Engineering and Tunnels, vol. 3, no. 5, pp. 10-14+60, 2010.

[6] C. C. Xia, X. H. Wang, and S. Z. He, "Comparative research on construction scheme of tunnel under runway," Chinese Journal of Underground Space and Engineering, vol. 4, no. 2, pp. 319-324, 2007.

[7] R. Jeffcoate, Z. H. Cai, and J. S. Chen, "Construction of underground baggage transfer system at London heathrow airport," Underground Space, vol. 20, no. 2, pp. 67-70, 2000.

[8] M. Tegelkanp, P. Wittke-Gattermann, M. Wittke, and W. Martin, "Tunneling under Stuttgart airport runway," Word tunnelling, vol. 16, no. 8, pp. 317-321, 2003.

[9] S. Ruan, "Study on the scheme of subway tunnel passing under non-stop airport," Railway Investigation and Surveying, vol. 46, no. 5, pp. 62-67, 2020.

[10] Z. Luo, Y. Tao, X. Gong, and B. Zou, "Soil compacting displacements for two jacked piles considering shielding effects," Acta Geotechnica, vol. 15, no. 8, pp. 2367-2377, 2020.

[11] Z. X. Wang, B. Wang, H. Li, Y. B. Fu, and J. S. Wen, "The additional stress of layered foundation caused by aircraft load and its influence scope on the underpass tunnel," China Civil Engineering Journal, vol. 53, no. S2, pp. $258-264+271,2020$.

[12] H. Zhang and J. M. Ling, "Shield construction control based on the functional requirements of concrete pavement in an airport flight zone," Modern Tunnelling technology, vol. 52, no. 1, pp. 150-155, 2015.

[13] H. X. Zhang, M. X. Zhang, X. H. Wang, and L. Li, "Analysis of settlement characteristics of double line shield tunnel passing through airport runway," Railway Standard Design, vol. 64, no. 12, pp. 114-119, 2020.

[14] L. Jiang, "Aircraft equivalent load calculation of pipe gallery and underpass structure under apron," China Municipal Engineering, vol. 5, no. 7, pp. 98-102, 2020.

[15] CAAC Airport Construction Corporation, MH/T 5004-2010 Specifications for Airport Cement Concrete Pavement Design, Civil Aviation Administration of China, Beijing, China, 2010.

[16] T. Benz, Small-strain Stiffness of Soils and its Numerical Consequences, Ph.D. thesis, University of Stuttgart, Stuttgart, Germany, 2006.

[17] J. X. Zhang, G. Zhao, L. Zhang, and H. Jiang, "Application of HSS model in shield simulation and parameter sensitivity research," Chinese Journal of Underground Space and Engineering, vol. 16, no. S2, pp. 618-625, 2020.

[18] Y. Wang, F. Geng, S. Yang, H. Jing, and B. Meng, "Numerical simulation of particle migration from crushed sandstones during groundwater inrush," Journal of Hazardous Materials, vol. 362, pp. 327-335, 2019.

[19] W. J. Robinson and I. L. Howard, "Implications of incorporating geosynthetics in airfield pavements," Transportation Geotechnics, vol. 28, no. 4, pp. 1-10, 2021. 